\title{
PRODUÇÃO, PURIFICAÇÃO, CLONAGEM E APLICAÇÃo DE ENZIMAS LÍTICAS
}

\section{Luciana Francisco Fleuri* e Hélia Harumi Sato}

Departamento de Ciência de Alimentos, Faculdade de Engenharia de Alimentos, Universidade Estadual de Campinas, CP 6121, 13083-862 Campinas - SP

Recebido em 7/6/04; aceito em 3/3/05; publicado na web em 11/7/05

\begin{abstract}
PRODUCTION, PURIFICATION, CLONING AND APPLICATION OF LYTIC ENZYMES: Lytic enzymes such as $\beta-1,3$ glucanases, proteases and chitinases are able to hydrolyse, respectively, $\beta-1,3$ glucans, mannoproteins and chitin, as well as the cell walls of many yeast species. Lytic enzymes are useful in a great variety of applications including the preparation of protoplasts; the extraction of proteins, enzymes, pigments and functional carbohydrates; pre-treatment for the mechanical rupture of cells; degradation of residual yeast cell mass for the preparation of animal feed; analysis of the yeast cell wall structure and composition; study of the yeast cell wall synthesis and the control of pathogenic fungi. This review presents the most important aspects with respect to lytic enzymes, especially their production, purification, cloning and application.
\end{abstract}

Keywords: $\beta-1,3$ glucanases; lytic proteases; chitinases.

\section{INTRODUÇÃO}

A parede celular da levedura Saccharomyces cerevisiae é formada por três componentes principais: glucana, um polímero de $\beta-1,3$ e $\beta-1,6$ glicose (48-60\%), mananaproteínas (20-23\%) e quitina, um polímero de $\beta-1,4 \mathrm{~N}$-acetilglicosamina $(0,6-2,7 \%)^{1-3}$. A parede celular possui duas camadas principais: uma externa, composta de mananaproteínas e uma interna, de glucana ${ }^{4,5}$.

Muitos microrganismos lisam a parede celular de leveduras. As enzimas envolvidas na lise de leveduras são $\beta-1,3$ glucanases, $\beta-1,6$ glucanases, mananases, proteases e quitinases. Essas enzimas agem sinergicamente na lise da parede celular, mas somente duas são essenciais para o rompimento da célula: a protease lítica específica, que degrada a camada externa de mananaproteína e a $\beta-1,3$ glucanase lítica, que degrada a camada interna de glucana ${ }^{6-8}$.

As enzimas que lisam a parede celular de leveduras têm aplicações biotecnológicas na preparação de protoplastos para melhoramento genético de leveduras e no aproveitamento de massa celular de levedura para extração de proteínas, enzimas e pigmentos. A lise enzimática de células de microrganismos também tem potencial de aplicação no tratamento de massa celular de levedura residual de indústrias de fermentação para preparação de ração animal, na obtenção de carboidratos funcionais da parede celular (glucana e manana) e no pré-tratamento para ruptura mecânica de células aumentando a eficiência e reduzindo o requerimento de energia ${ }^{9}$.

As enzimas líticas têm sido utilizadas também como ferramenta para determinação da composição da parede celular de leveduras e no estudo do mecanismo da síntese da parede celular para controle de leveduras patogênicas.

As enzimas líticas são capazes de lisar a parede celular de Saccharomyces cerevisiae, Candida sp. e outros gêneros de leveduras, o que amplia o campo de utilização dessas enzimas.

Este trabalho tem como objetivo revisar os principais aspectos relacionados à produção, purificação, clonagem e aplicações das enzimas líticas.

\footnotetext{
*e-mail: luciana@fea.unicamp.br
}

\section{COMPOSIÇÃO DA PAREDE CELULAR DE LEVEDURAS}

A parede celular de leveduras tem muitas funções: proteção física, estabilidade osmótica, suporte de enzimas, adesão célula/ célula e barreira de permeabilidade seletiva ${ }^{10}$. Além disso, promove rigidez e transporte de nutrientes para o citoplasma, proporcionando a integridade, o metabolismo e o crescimento celular. Constitui cerca de 15 a $25 \%$ da massa seca da célula e não é uma estrutura estática e sim, uma estrutura em constante crescimento e mudança. Os componentes da parede celular são sintetizados e unidos entre si; estruturas especializadas, como os septos são formados em sincronia com o crescimento e divisão celular ${ }^{11}$.

A parede celular de leveduras é formada por uma camada de mananaproteínas que sobrepõe a camada de glucana, o que explicaria a resistência das células vivas de leveduras ao ataque das misturas enzimáticas elaboradas por alguns microrganismos ${ }^{4,5,12}$.

A parede celular de Saccharomyces sp. é formada por três componentes principais: glucana, um polímero de $\beta-1,3$ e $\beta-1,6$ glicose (48-60\%), mananaproteínas $(20-23 \%)$ e quitina, um polímero de $\beta-1,4 \mathrm{~N}$-acetilglicosamina $(0,6-2,7 \%)^{1-3}$. As mananaproteínas estão localizadas na parte externa da parede celular e são compostas por polímero de manose com ligações $\alpha$ $1,2, \alpha-1,3$ e $\alpha-1,6$, que estão covalentemente ligadas a peptídeos formando glicopeptídeos ${ }^{13-15}$.

Kapteyn et al. ${ }^{15}$, Pololo e Vai ${ }^{16}$ e Kapteyn et al. ${ }^{17}$ relataram que as proteínas, $\beta$-1,6 glucanas, $\beta-1,3$ glucanas e quitina da parede celular das leveduras estão interconectadas por ligações covalentes.

A parede celular é uma estrutura dinâmica ajustável durante o ciclo celular e em resposta às condições ambientais como nutrientes, disponibilidade de $\mathrm{O}_{2}$, temperatura e $\mathrm{pH}^{11,18}$. Perturbações na parede celular de leveduras desencadeiam mecanismos de reparo que reorganizam toda a estrutura molecular, para preservar a integridade da célula ${ }^{18,19}$.

\section{Mananaproteínas}

A camada de mananaproteínas tem função de proteger a célula contra fatores externos e é responsável pela porosidade da parede celular, enquanto que a camada de glucana é responsável pela es- 
trutura da parede celular perante choques mecânicos e desequilíbrios osmóticos ${ }^{7,11}$.

Cabib et al. ${ }^{11}$ sugeriram a existência de ligações cruzadas entre polissacarídeos e mananaproteínas e que a $\beta-1,3$ glucana e quitina estão conectadas por uma ligação $\beta-1,4$ entre um grupo redutor final de $\mathrm{N}$-acetilglicosamina da quitina e um grupo não redutor da glicose da glucana. Os autores verificaram também a presença de um núcleo central de mananaproteína, em que a quitina e a $\beta-1,3$ glucana estão conectadas preferencialmente a cadeias curtas de $\beta$ 1,6 glucanas. Há evidências que as mananaproteínas estão retidas na parede celular por ligações indiretas com as $\beta-1,3$ glucanas e estas, ligadas preferencialmente a cadeias curtas de $\beta-1,6$ glucanas e, provavelmente, porções residuais de glicosilfosfatidilinositol.

Segundo Mrsa et al..$^{20,21}$, a parede celular de Saccharomyces contém mais de 20 tipos de mananaproteínas que desempenham papéis diferentes na construção, preservação, modificação da estrutura e interação das células com suas adjacências como, por ex., as interações intercelulares durante a aglutinação ou floculação. As mananaproteínas podem ser divididas em três grupos: proteínas unidas por pontes dissulfeto ou ligações não covalentes com polissacarídeos estruturais da parede (a maioria dessas proteínas apresentam atividades enzimáticas e podem ser extraídas por meio de aquecimento com SDS e mercaptoetanol ou pelo ditiotreitol); proteínas ligadas covalentemente principalmente às $\beta$-glucanas e que podem somente ser extraídas pela lise da parede celular com diferentes preparações de glucanases, como zymolyase ou laminarinase (a função fisiológica dessas proteínas não é conhecida), e, proteínas, provavelmente, ligadas de forma covalente à parede celular e que podem ser extraídas com $\mathrm{NaOH} 30 \mathrm{mM}$ (quatro proteínas pertencentes a esse grupo estão sendo estudadas mais detalhadamente).

\section{$\beta-1,3$ glucana}

Manners et al. ${ }^{22}$ descreveram a $\beta-1,3$ glucana insolúvel em álcali contendo 3-6\% de ramificações $\beta-1,6$ como o principal componente estrutural da parede celular de leveduras. Estudos microscópicos mostraram a agregação destas microfibras na parte interna da parede celular. A glucana solúvel em álcali tem estrutura química semelhante à insolúvel, entretanto, apresenta maior número de ramificações $\beta-1,6$. A glucana álcali-solúvel representa aproximadamente $20 \%$ da parede celular e a análise estrutural revelou a presença de $80-85 \%$ de ligações $\beta$-D-1,3; 8 - $12 \%$ de ligações $\beta$ D-1,6 e 3-4\% de resíduos de ramificações ligados por C-1, C-3 e C-6.

Kopecká et al. ${ }^{23}$ estudaram a ultraestrutura da parede celular de isolados de $S$. cerevisiae durante as fases exponencial e estacionária de crescimento, usando $\beta-1,3$ glucanases. Os autores obtiveram duas importantes informações: as regiões de brotamento de leveduras são estruturas resistentes ao efeito dessa enzima e os componentes fibrilares das leveduras são constituídos de glucanas com ligações $\beta-1,3$, uma vez que as microfibrilas desapareceram após tratamento com $\beta-1,3$ glucanase. Os autores, então, relataram que as moléculas de glucana permitem a associação das cadeias mais afastadas de polissacarídeos com outras moléculas de ramificações superficiais, dando origem a um componente fibrilar contínuo.

Estudos da parede celular de leveduras com a utilização de microscópio eletrônico permitiram a Kreger e Kopeckáa ${ }^{4}$ confirmarem a posição interna da fração de glucana.

Segundo Hinton e Pressey ${ }^{25}$, as glucanas podem ser encontradas em microrganismos e plantas superiores como principais constituintes da parede celular, como material citoplasmático ou de reserva vacuolar e como substâncias extracelulares. As glucanas são polímeros não cíclicos de anidroglicose unidos por ligações $\beta-1,3$ glicosídicas contendo ramificações $\beta-1,6$, as quais pertencem a uma das classes mais abundantes de polissacarídeos.

A parede celular de Saccharomyces cerevisiae contém duas frações de $\beta-1,3$ glucana (uma solúvel em álcali e outra insolúvel) e uma fração de $\beta-1,6$ glucana com poucas ligações $\beta-1,3$ (insolúvel em álcali e solúvel em soluções diluídas de ácido). As $\beta-1,3$ glucanas têm tamanho estimado de 1.500 resíduos de glicose, enquanto que as $\beta-1,6$ glucanas são menores, apresentando de 150 a 200 resídu$\mathrm{os}^{10}$. Muitos estudos têm mostrado que estes componentes, depois de serem depositados na parede, são rearranjados para formarem um complexo integrado. Os rearranjos podem ocorrer através de glicosiltransferases, as quais introduzem ramificações nos polissacarídeos lineares. Há evidências de ligações entre mananaproteínas e quitina. A insolubilidade da glucana em álcali é explicada pela presença de ligações covalentes entre glucana e quitina, uma vez que a degradação da quitina por quitinase dissolve completamente a glucana em álcali. Foi demonstrado que ocorre a formação de ligação $\alpha-1,6$ glicosídica entre glucana e quitina na parede celular de Candida albicans, mas em Saccharomyces cerevisiae a natureza da ligação é desconhecida ${ }^{2}$.

\section{Quitina}

A quitina é um polímero de $\mathrm{N}$-acetilglicosamina com ligações $\beta-1,4$ encontrada em carapaças de insetos, parede celular de fungos e crustáceos ${ }^{26}$. Estudos de difração de raio-X demonstraram que se refere a uma estrutura cristalina altamente ordenada e insolúvel em água 27.

Na maioria dos fungos a quitina é o maior componente estrutural da parede celular, sendo, portanto, susceptível a inúmeras espécies de bactérias, actinomicetos e fungos que podem agir como antagonistas devido à produção de enzimas quitinolíticas ${ }^{28}$. É o segundo biopolímero mais abundante depois da celulose e está geralmente ligada a outros polissacarídeos e proteínas ${ }^{26}$.

Em leveduras, a quitina é encontrada predominantemente em septos primários e em volta do círculo de constrição entre a célula mãe e a jovem. Cerca de $90 \%$ da quitina está localizada na cicatriz de brotamento e o restante, na parede celular ${ }^{2}$.

\section{PRODUÇÃO DE ENZIMAS LÍTICAS}

As $\beta-1,3$ glucanases, proteases e quitinases estão agrupadas na classe das hidrolases.

A $\beta-1,3$ glucanase (E.C. 3.2.1.39) (1,3- $\beta$-D-glucana glucanohidrolase), também denominada de glucana-endo-1,3- $\beta$-Dglicosidase, catalisa a reação de hidrólise das ligações $\beta$-Dglicosídicas da $\beta-1,3$ glucana. Atua sobre laminarina, paramylona e pachymana, quando utilizadas como substrato (Figura 1).

A protease (3.4.21.12) também denominada de $\alpha$-endopeptidase lítica, catalisa a reação de hidrólise de proteínas. Atua preferencialmente sobre elastina e em $\mathrm{Ala}^{+} \mathrm{e} \mathrm{Val}{ }^{+}$da parede celular (Figura 3).

A quitinase (3.2.1.14) \{Poli[1,4-(N-acetil- $\beta$-D-glicosamina $)]$ glucanoidrolase $\}$ catalisa reações de hidrólise das ligações $\beta-1,4$ de N-acetil- $\beta$-D-glicosamina da quitina e de quitodextrinas (Figura 2).

Muitos microrganismos, como bactérias, fungos e leveduras são capazes de produzir $\beta-1,3$ glucanases, proteases e quitinases, que hidrolisam os componentes da parede celular de leveduras e causam a lise celular. A maioria deles necessita da presença de indutores para síntese de enzimas de interesse (Tabela 1).

As bactérias Cytophaga johnsonii ${ }^{29}$, Arthrobacter luteus ${ }^{30}$, Oerskovia sp. $\mathrm{CK}^{31,32}$, Rarobacter faecitabidus ${ }^{33}$, Rarobacter 

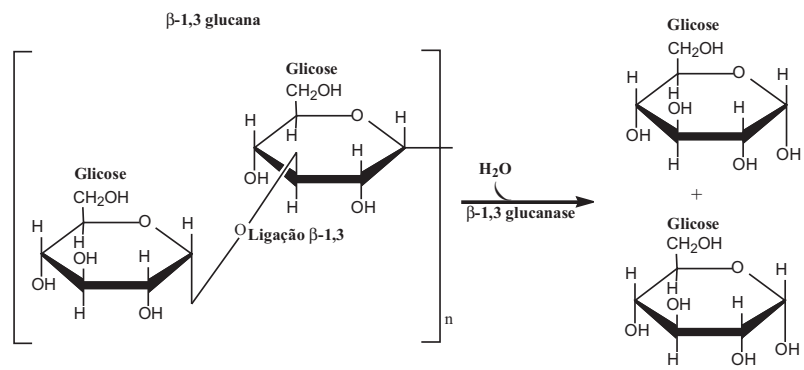

Figura 1. Hidrólise da $\beta-1,3$ glucana pela $\beta-1,3$ glucanase
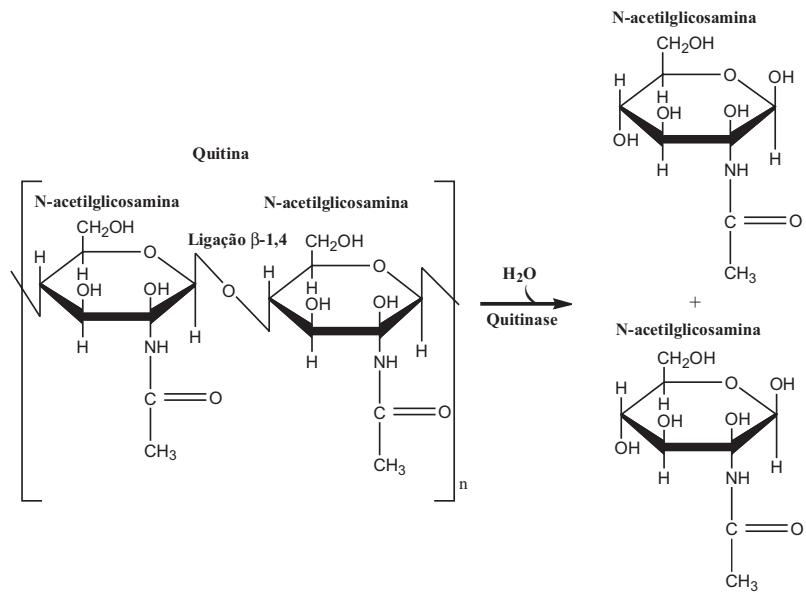

Figura 2. Hidrólise da quitina pela quitinase

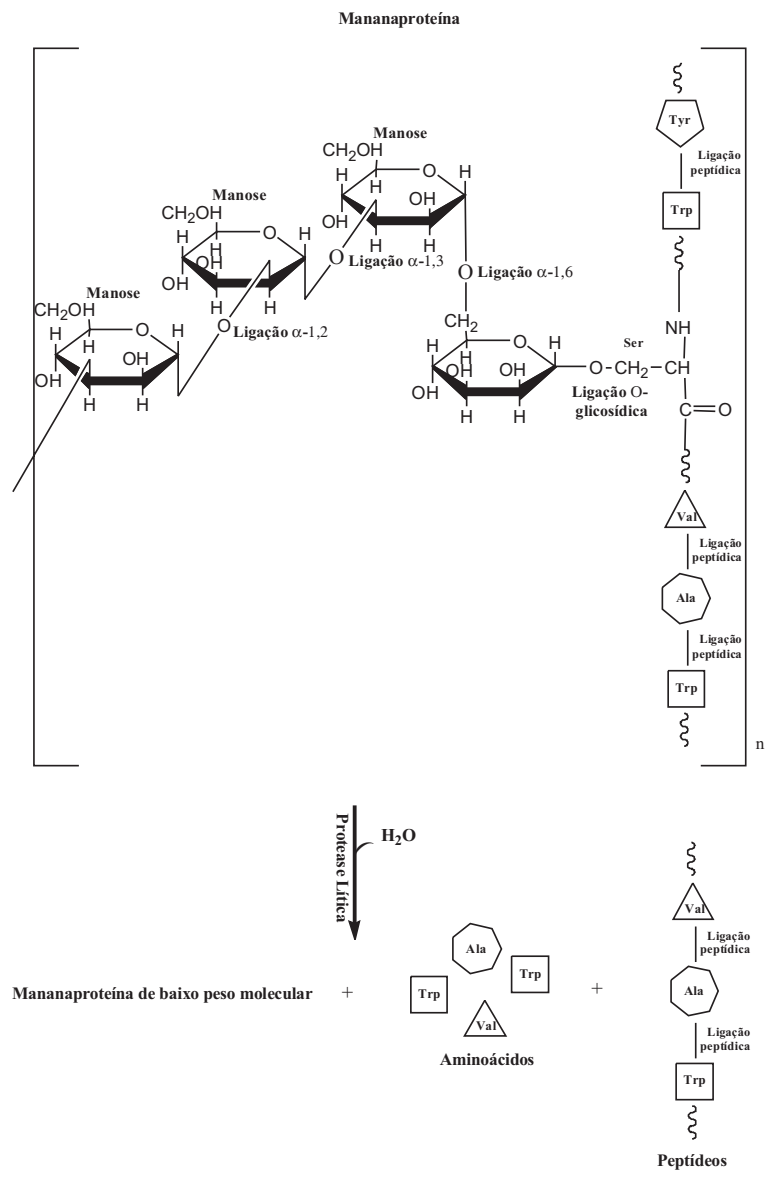

Figura 3. Hidrólise da mananaproteína pela protease lítica incanus $^{34}$, Cellulomonas cellulans 191 (Cellulosimicrobium cellulans $)^{35,36}$ produzem enzimas $\beta-1,3$ glucanases e proteases capazes de lisar células de leveduras (Tabela 2).

Estes microrganismos têm sido isolados a partir de lodo ativado de sistemas de tratamento de água de indústrias de alimentos e bebidas alcoólicas ${ }^{37}$.

Bacon et al. ${ }^{29}$ relataram que o microrganismo Cytophaga johnsonii produziu enzimas capazes de lisar células de leveduras pré-tratadas com tiol na presença de células autoclavadas ou tratadas com álcali, parede celular e glucana de levedura como indutores. A purificação do sobrenadante da cultura através de cromatografia em coluna mostrou a presença de dois tipos de endo- $\beta-1,3$ glucanases e muitas $\beta$-1,6 glucanases.

Kitamura e Yamamoto ${ }^{38}$ relataram que o microrganismo Arthrobacter luteus, isolado de resíduos de cervejarias, cresceu em meio contendo células de levedura ou $\beta-1,3$ glucana e produziu enzimas com atividade de lise de leveduras. O conjunto destas enzimas foi denominado zymolyase e requeria polímeros lineares de glicose com ligações $\beta-1,3$ como substrato específico. Os autores verificaram que o polissacarídeo termo-tratado pachymana e a glucana de levedura foram hidrolisados por zymolyase a unidades de laminaripentaose.

Kobayashi et al. ${ }^{46}$ estabeleceram um método para produção e preparação de um complexo enzimático que degrada parede celular de leveduras produzido por espécies de Rhizoctonia, em escala comercial. A produção da enzima bruta em pó, em batelada de 80 $\mathrm{kg}$, mostrou-se viável. Esta preparação enzimática foi avaliada para uso industrial.

Yamamoto et al. ${ }^{47}$ isolaram microrganismos que lisam leveduras a partir do lodo ativado de tanques de sistemas de tratamento de água de indústrias de alimentos e de bebidas alcoólicas. Dez linhagens que puderam crescer em meio nutriente normal pertenciam aos gêneros Streptomyces sp., Oerskovia sp. e Bacillus sp.

Yamamoto et al. ${ }^{48}$ isolaram trinta e seis linhagens de bactérias que lisam leveduras de lodo ativado de resíduos de tratamento de água. Estes microrganismos aderiram, aglutinaram e lisaram às células viáveis de todas as espécies de Saccharomyces e Hansenulla e algumas espécies de Candida. Esses microrganismos não aderiram ou lisaram células viáveis de Rhodotorula, Cryptococcus e Trichosporon.

Andrews e Asenjo ${ }^{4}$ verificaram que as enzimas $\beta-1,3$ glucanase e protease do sistema lítico da bactéria Oerskovia xanthineolytica LLG109 são capazes de lisar e romper totalmente as células de leveduras. Esta bactéria apresentou taxa de glucanase-protease maior que a de outras cepas. Quando cultivada em sistema contínuo, a bactéria Oerskovia xanthineolytica apresentou produtividade e concentração de enzimas maiores que quando cultivada em batelada. O sistema de enzimas líticas está sujeito à repressão catabólica pela glicose e mostrou-se induzível pela glucana da levedura. Na fermentação da linhagem Oerskovia sp. em cultura contínua, a glicose pode ser utilizada como meio de crescimento com concentração relativamente baixa do indutor.

Yamamoto et al. ${ }^{34}$ isolaram no Brasil, linhagens de bactérias que lisam leveduras a partir de solo, flores, frutos e outras fontes. Destas linhagens, 46 foram identificadas como Rarobacter. Essas linhagens de Rarobacter apresentaram a capacidade de se aglutinarem com células viáveis de $S$. cerevisiae e exigiam composto heme para crescimento aeróbico. Outras quatro bactérias gram positivas não exigiam grupo heme para crescimento aeróbico; duas delas foram identificadas como Oerskovia, uma como Arthrobacter e a quarta não foi identificada.

Santos $^{35}$ estudou a produção de $\beta-1,3$ glucanase e protease por microrganismos que lisam a parede celular de levedura. As linhagens FXX e Cellulosimicrobium cellulans 191 apresentaram maior produção de $\beta-1,3$ glucanase, enquanto que a linhagem Oerskovia sp. 
Tabela 1. Microrganismos produtores de enzimas líticas e indutores utilizados para produção das enzimas líticas

\begin{tabular}{|c|c|c|}
\hline Microrganismo lítico & Fonte de carbono (indutor) & Enzima(s) produzida(s) \\
\hline Cythophaga johnsonii ${ }^{29}$ & Parede celular de levedura de panificação & $\beta-1,3$ glucanase e $\beta-1,6$ glucanase \\
\hline Rhizopus chinensis $\mathrm{R}-69^{14}$ & Células de leveduras de panificação ou farelo & Endo e exo $\beta-1,3$ glucanase \\
\hline Oerskovia xanthineolytica ${ }^{6}$ & $\begin{array}{l}\text { Glucana insolúvel em meio alcalino, levedura } \\
\text { autoclavada e glicose }\end{array}$ & $\beta-1,3$ glucanase e protease alcalina \\
\hline Streptomyces rutgersensis $\mathrm{H}-46^{39,40}$ & Glicose e extrato de soja & Enzimas bacteriolíticas \\
\hline Oerskovia sp. $^{8}$ & Glucana e parede celular de leveduras & $\beta-1,3$ glucanase \\
\hline $\begin{array}{l}\text { Várias espécies de Acremonium e } \\
\text { Cephalosporium }^{41,42}\end{array}$ & Glicose e laminarina ou pustulana & $\beta-1,3$ glucanase \\
\hline Trichoderma harzianum ${ }^{43}$ & $\begin{array}{l}\text { Parede celular purificada } \\
\text { Quitina, quitosana, N-acetilglicosamina e laminarina }\end{array}$ & $\begin{array}{l}3 \text { isoformas de } \beta-1,3 \text { glucanase } \\
1 \text { isoforma de } \beta-1,3 \text { glucanase }\end{array}$ \\
\hline Trichoderma asperellum ${ }^{44}$ & Parede celular de Rhizoctonia solani & $\beta-1,3$ glucanases \\
\hline Paecilomyces lilacinus ${ }^{45}$ & $\begin{array}{l}\text { Gema de ovo } \\
\text { Quitina }\end{array}$ & $\begin{array}{l}\text { Proteases } \\
\text { Quitinases }\end{array}$ \\
\hline
\end{tabular}

Tabela 2. Sistemas enzimáticos líticos de microrganismos

\begin{tabular}{|c|c|c|c|c|}
\hline Microrganismos líticos & Enzimas & pH ótimo & $\begin{array}{l}\text { Temperatura } \\
\text { ótima }\left({ }^{\circ} \mathrm{C}\right)\end{array}$ & Microrganismos lisados \\
\hline $\begin{array}{l}\text { Arthrobacter luteus, } \\
\text { Oerskovia xanthineolytica } \\
\text { (zymolyase) })^{6,49,50}\end{array}$ & $\begin{array}{c}\beta-1,3 \text { glucanase } \\
\text { Protease } \\
\text { Atividade na célula } \\
\text { de levedura integral }\end{array}$ & $\begin{array}{c}5,0-6,5 \\
9,0-10,0 \\
7,5\end{array}$ & $\begin{array}{l}45-60 \\
35 \\
30-35\end{array}$ & $\begin{array}{l}\text { Saccharomyces sp., Candida sp., } \\
\text { Hansenula sp., Pichia sp. e outras leveduras }\end{array}$ \\
\hline Arthrobacter sp. G1 ${ }^{51}$ & - & - & - & $\begin{array}{l}\text { Saccharomyces fragilis NCYC 587, } \\
\text { Torulopsis colliculosa NCYC 141, } \\
\text { Candida utilis NCYC } 707\end{array}$ \\
\hline Cellumonas cartae $191^{35}$ & $\begin{array}{l}\beta-1,3 \text { glucanase } \\
\text { Protease } \\
\text { Atividade na célula } \\
\text { de levedura integral }\end{array}$ & $\begin{array}{c}4,5 \\
8,0 \\
7,0-7,5\end{array}$ & $\begin{array}{c}55 \\
50 \\
30-35\end{array}$ & $\begin{array}{l}\text { Kluyveromyces marxianus NCYC587, } \\
\text { Pachysolen tannophilus NRRL 2460, } \\
\text { Saccharomyces capensis NCYC 761, } \\
\text { S.cerevisiae KL 88, Candida glabrata } \\
\text { NCYC 388, Debaryomyces vanrij NCYC } 577\end{array}$ \\
\hline Cytophaga NCIB $9497^{4}$ & $\begin{array}{l}\text { Atividade na célula } \\
\text { de levedura integral }\end{array}$ & 9,0 & $45-55$ & $\begin{array}{l}\text { Saccharomyces cerevisiae, Bacillus sp., } \\
\text { Corynebacteria, E. coli }\end{array}$ \\
\hline Oerskovia $\mathrm{CK}^{31,32}$ & $\begin{array}{c}\beta-1,3 \text { glucanase } \\
\text { Protease } \\
\text { Atividade na célula } \\
\text { de levedura integral }\end{array}$ & $\overline{-}$ & $\begin{array}{l}35-40 \\
60 \\
35-40\end{array}$ & Saccharomyces cerevisiae \\
\hline Rhizoctonia sp. ${ }^{46}$ & $\begin{array}{c}\beta-1,3 \text { glucanase } \\
\text { Protease } \\
\text { Atividade na célula } \\
\text { de levedura integral }\end{array}$ & $\begin{array}{l}5,5 \\
6,5 \\
6,0\end{array}$ & $\begin{array}{c}55-60 \\
40 \\
40\end{array}$ & $\begin{array}{l}\text { Candida sp., Saccharomyces sp., } \\
\text { Hansenula } \text { sp. }\end{array}$ \\
\hline Streptomyces sp. $1228^{52}$ & $\beta-1,3$ glucanase & $5,5-6,0$ & $50-55$ & $\begin{array}{l}\text { Candida utilis, Saccharomyces } \\
\text { carlsbengensis, Schizosaccharomyces pombe }\end{array}$ \\
\hline
\end{tabular}

4 apresentou maior produção de protease. A maior produção de $\beta$ 1,3 glucanase foi verificada em meio de cultivo contendo parede celular de levedura extraída mecanicamente como indutor, enquanto que a maior produção de protease ocorreu com levedura autoclavada, lavada e liofilizada.

Gacto et al..$^{53}$ estudaram o crescimento do actinomiceto Micromonospora chalcea, em meio contendo laminarina como fonte de carbono para induzir a produção de um sistema de enzimas extracelulares capazes de lisar células de várias espécies de levedura.

Fleuri ${ }^{54}$ estudou a produção de $\beta-1,3$ glucanases, proteases líticas e quitinases pelas linhagens B1, B22, B26, FXX, Oerskovia sp. 4 e Cellulosimicrobium cellulans 191, em meios de cultura contendo diferentes indutores e aplicação na lise de leveduras. A maior produção de protease lítica foi obtida com as linhagens bacterianas B26 e 191, em meio de cultivo contendo $8 \%$ de levedura seca. As linhagens 
B1 e 191 apresentaram maior produção de $\beta-1,3$ glucanase entre as linhagens testadas, em meio de cultivo contendo $1 \%$ de parede celular de levedura; enquanto que a linhagem 191 apresentou maior produção de quitinase entre as linhagens testadas, em meio de cultivo contendo $1,5 \%$ de quitina neutralizada. As preparações de $\beta-1,3$ glucanase das linhagens B1 e C. cellulans 191 obtidas do sobrenadante do meio de cultura, por meio de fracionamento com sulfato de amônio, apresentaram atividade de lise das leveduras Saccharomyces cerevisiae KL-88, Kluyveromyces marxianus NCYC 587, Hansenula mrakii NCYC 500 e Candida glabrata NCYC 388, sendo que Kluyveromyces marxianus e Hansenula mrakii apresentaram-se mais susceptíveis às $\beta-1,3$ glucanases que a linhagem de Saccharomyces cerevisiae. Entre as linhagens testadas, a levedura Candida glabrata mostrou-se mais resistente à atividade de lise das $\beta-1,3$ glucanases.

$\mathrm{O}$ extrato bruto de quitinase, obtido a partir do cultivo de Trichoderma harzanium TUBF 781 em fermentação semi-sólida em meio otimizado, mostrou atividade antifúngica contra uma série de linhagens de fungos selvagens, como Aspergillus sp., Rhizopus sp. e Mucor sp., mostrando maior eficácia contra Aspergillus niger ${ }^{55}$.

Kenji et al..$^{56}$ estudaram a produção de três endoquitinases por Bacillus stearothermophilus $\mathrm{CH}-4$ em meio de cultivo contendo quitina e verificaram que as enzimas responsáveis pela degradação da quitina são quitinase A (endo-ação), quitinase B (exo-ação) e $\mathrm{N}$-acetilglicosaminidases.

A lise dos componentes da parede celular de leveduras pelas enzimas produzidas por microrganismos pode variar dependendo dos estágios de crescimento celular ${ }^{57}$ e conforme o gênero e a espécie da levedura ${ }^{58}$. A lise enzimática das células de levedura acontece em passos progressivos e depende do sinergismo entre protease e $\beta-1,3$ glucanase. A protease ataca a camada externa de mananaproteína, permitindo o acesso da $\beta-1,3$ glucanase à camada de $\beta$ glucana, implicando no rompimento celular por diferença de pressão osmótica ${ }^{6,9,51,59,60}$.

Os microrganismos do gênero Arthrobacter produzem dois tipos de $\beta-1,3$ glucanases. A glucanase I causa lise em células jovens na presença de $\beta$-mercaptoetanol e $0,6 \mathrm{M}$ de $\mathrm{KCl}$ como estabilizador osmótico. A glucanase II é similar à encontrada em fluido de cultura de Bacillus circulans. Na dissolução da parede celular de leveduras por glucanase I, a enzima ataca a glucana liberando fragmentos de vários tamanhos que servem como substratos para a glucanase II. As $\beta$-glucanases são estáveis em ampla faixa de $\mathrm{pH}$, mas perdem rapidamente a atividade em temperaturas acima de $60{ }^{\circ} \mathrm{C}$; apresentam $\mathrm{pH}$ ótimo de atividade na faixa de 5,5 a $6,5^{30}$.

Obata et al..$^{32}$ relataram que a linhagem Oerskovia sp. CK produz três tipos de enzimas designadas F-L, F-0 e F-2 que estão envolvidas na lise da parede celular de leveduras. A enzima F-L mostrou alta atividade lítica em células viáveis de levedura, mas fraca atividade sobre a glucana de levedura. As enzimas F-0 e F-2 mostraram baixa ou nenhuma atividade lítica, mas alta atividade de $\beta-1,3$ glucanase. Os resultados evidenciaram que as enzimas F-0 e F-2 não são eficientes na lise de leveduras, devido à inacessibilidade espacial à camada de glucana. No entanto, $\mathrm{o}$ tratamento com a enzima F-L com solução alcalina ou com reagentes redutores modificaram a célula, permitindo o acesso de F-0 e F-2 à camada de glucana e possibilitando a lise da célula; foi observado efeito sinérgico entre as enzimas F-L e F-0 ou F-L e F-2. A protease F-L produzida por Oerskovia sp. CK possui alto efeito sinérgico com a enzima $\beta-1,3$ glucanase na lise de leveduras.

Rowley e Bull ${ }^{51}$ estudaram uma linhagem de Arthrobacter com alta capacidade para lisar células vivas de Saccharomyces fragilis. O complexo enzimático extracelular produzido pelo microrganismo continha $\beta-1,3$ glucanase, mananase, manose hidrolase e atividade proteolítica.
A zymolyase, preparação comercial para lise da parede celular de leveduras, é obtida a partir Arthrobacter luteus. Esse microrganismo foi reclassificado como Oerskovia xanthineolytica ${ }^{61}$. A zymolyase é uma preparação enzimática composta de duas frações: a zymolyase A, que é uma $\beta-1,3$ glucanase e a zymolyase $B$, que é uma protease alcalina e provavelmente também uma serina protease. A $\beta-1,3$ glucanase (zymolyase A) não diminui a turbidez nem o número de células de uma suspensão de leveduras. A protease (zymolyase B) diminui a turbidez, mas não altera o número de células da suspensão. No entanto, a ação cooperada de zymolyase A e B tem como efeito alta atividade lítica, lisando completamente as células de leveduras ${ }^{62}$.

A bactéria Rhizoctonia solani produz enzimas líticas capazes de lisar a parede celular de leveduras. As enzimas foram separadas em quatro frações: L-1, L-2, L-3 e L-4. Três delas foram consideradas $\beta$ 1,3 glucanases líticas. A fração L-3 mostrou alta atividade de protease. A protease purificada L-3 sozinha, assim como as outras $\beta-1,3$ glucanases líticas foram capazes de lisar células intactas e parede celular isolada de S. cerevisiae. A separação completa da protease lítica de Rhizoctonia solani não foi importante apenas para esclarecer a ação hidrolítica da parede celular de levedura, mas também para elucidar a estrutura da parede ${ }^{63}$.

Ryan e Ward ${ }^{64}$ verificaram que a enzima $\beta-1,3$ glucanase de Basideomycete aphyllophoroles possui alta atividade lítica em leveduras. Quando usada em combinação com papaína na lise de leveduras, 90 a $95 \%$ da massa seca das leveduras foram solubilizadas. Em comparação com estudos envolvendo três $\beta-1,3$ glucanases, a atividade de laminarinase não foi bem correlacionada com a atividade lítica em leveduras. $O$ mecanismo da $\beta-1,3$ glucanase do $B$. aphyllophoroles em glucana isolada de levedura foi caracterizado pela alta taxa de produção de laminaribiose.

\section{PURIFICAÇÃO DE ENZIMAS LÍTICAS}

As preparações enzimáticas comerciais como a lyticase de Arthrobacter luteus e lyticase recombinante expressa em Escherichia coli para lise de leveduras e para obtenção de protoplastos são encontradas nas formas bruta e parcialmente purificada (Tabela 3).

\section{CLONAGEM}

A clonagem ultimamente tem sido uma ferramenta muito importante e útil para enzimologistas e outros pesquisadores. Em relação às enzimas líticas, a disponibilidade de seqüências nucleotídicas e, conseqüentemente, de famílias de genes, possibilita um maior entendimento do papel e do modo de ação dessas enzimas na degradação da parede celular de leveduras, além de possibilitar a comparação com enzimas de outros organismos. Estudos mais apurados sobre as relações estruturais e funcionais dessas enzimas permitem obter enzimas líticas apropriadas para permeabilização celular e recuperação seletiva de proteínas das células de leveduras, não somente de $S$. cerevisiae, mas também de leveduras cada vez mais importantes no ramo biotecnológico, como Hansenula polimorpha, Pichia pastoris, entre outras ${ }^{74}$. Devido à importância das $\beta-1,3$ glucanases, muitos genes que codificam a produção desta enzima têm sido identificados, clonados e transferidos em um microrganismo competente. Técnicas de clonagem de DNA complementares (DNAc) combinadas com mecanismos de regulação da transcrição, utilização de vetores plasmidiais especialmente projetados e transformação em $E$. coli, também têm sido muito utilizadas para super produção de enzimas de interesse (Tabela 4). 
Tabela 3. Purificação e caracterização de enzimas líticas

\begin{tabular}{|c|c|c|c|c|}
\hline Microrganismo & Enzima purificada & $\begin{array}{l}\text { Métodos de purificação e } \\
\text { eletroforese }\end{array}$ & $\begin{array}{l}\text { Massa } \\
\text { molecular } \\
(\text { KDa })\end{array}$ & $\begin{array}{l}\text { Propriedades bioquímicas da } \\
\text { enzima } \\
\text { a- } \mathrm{pH} \text { ótimo: substrato } \\
\text { b- temperatura ótima } \\
\text { c- estabilidade } \\
\text { d- pI } \\
\text { e- } \mathrm{K}_{\mathrm{m}}: \text { substrato } \\
\text { f- } \mathrm{V}_{\mathrm{m}}: \text { substrato }\end{array}$ \\
\hline $\begin{array}{l}\text { Oerskovia xanthineolytica } \\
\text { LL-G10965 }\end{array}$ & $\beta-1,3$ glucanase & SDS-PAGE & 27,19 & $\begin{array}{l}\text { b- } 65^{\circ} \mathrm{C} \\
\mathrm{c}-55^{\circ} \mathrm{C} / 30 \mathrm{~min}\end{array}$ \\
\hline $\begin{array}{l}\text { Oerskovia xanthineolytica } \\
\text { TK- } 1^{66}\end{array}$ & $\beta-1,3$ glucanase & $\begin{array}{l}\text { Colunas DEAE-Sephacel, } \\
\text { DEAE-Toyopearl 650M e } \\
\text { Bio-Gel P-2 }\end{array}$ & 40 & $\begin{array}{l}\text { a- 7,5: laminarina } \\
\text { a- 5,5: glucana de levedura } \\
\text { d- } 6,5\end{array}$ \\
\hline Trichoderma harzanium ${ }^{67}$ & $\begin{array}{l}\text { Endo- } \beta-1,3 \\
\text { glucanase }\end{array}$ & $\begin{array}{l}\text { Coluna Sephacryl 300R e } \\
\text { focalização isoelétrica }\end{array}$ & 17 & d- 5,0 \\
\hline Trichoderma harzanium ${ }^{68}$ & $\beta-1,3$ glucanase & $\begin{array}{l}\text { Colunas Sephacryl S-200, } \\
\text { Fenil-Sepharose e CM-Sepharose, } \\
\text { SDS-PAGE }\end{array}$ & 29 & $\begin{array}{l}\text { a- } 4,4 \\
\text { b- } 50{ }^{\circ} \mathrm{C} \\
\text { e- } 1,72 \mathrm{mg} / \mathrm{mL} \text { : laminarina } \\
\text { f- } 3,10 \mathrm{U} / \mathrm{mL} \text { : laminarina }\end{array}$ \\
\hline $\begin{array}{l}\text { Cellulomonas cellulans } \\
191^{36}\end{array}$ & $\beta-1,3$ glucanase & $\begin{array}{l}\text { Ultrafiltração e coluna de } \\
\text { CM-Sepharose CL-6B, } \\
\text { SDS-PAGE }\end{array}$ & 17,1 & $\begin{array}{l}\text { a- } 5,5-6,5 \\
\text { b- } 55{ }^{\circ} \mathrm{C} \\
\text { c- pH } 5,5-6,5\end{array}$ \\
\hline $\begin{array}{l}\text { Cellulomonas cellulans } \\
191^{69}\end{array}$ & $\beta-1,3$ glucanase & $\begin{array}{l}\text { Ultrafiltração e coluna de } \\
\text { DEAE-Sepharose, SDS-PAGE }\end{array}$ & 57 & - \\
\hline Bacillus clausii ${ }^{70}$ & $\beta-1,3$ glucanase & $\begin{array}{l}\text { Colunas DEAE-Sepharose FF } \\
\text { e Sephacryl S-200HR, } \\
\text { SDS-PAGE }\end{array}$ & 71 & $\mathrm{c}-\mathrm{pH} 5,3-11,5$ \\
\hline $\begin{array}{l}\text { Cellulomonas flavigena } \\
\text { NTOU }^{71}\end{array}$ & quitinase & $\begin{array}{l}\text { Colunas Q cartridge e Superdex } \\
75 \mathrm{HR} \\
\text { Filtração em gel } \\
\text { SDS-PAGE }\end{array}$ & $\begin{array}{l}34,2 \\
32,5\end{array}$ & $\begin{array}{l}\text { a- } 10,0 \\
\text { b- } 50{ }^{\circ} \mathrm{C} \\
\text { c- } \mathrm{pH} 6,0-10,0 \text { até } 45^{\circ} \mathrm{C}\end{array}$ \\
\hline Metarhizium anisopliae ${ }^{72}$ & quitinase & $\begin{array}{l}\text { Precipitação com sulfato de } \\
\text { amônio e coluna } \\
\text { DEAE-Sephacel }\end{array}$ & 30 & $\begin{array}{l}\text { a- } 4,5-5,0 \\
\text { b- } 40-45{ }^{\circ} \mathrm{C} \\
\text { e- } 0,537 \mathrm{mmol} \text { :p-nitrofenol- } \\
\quad \beta \text {-diacetilquitobiose } \\
\text { f- } 4,86 \mathrm{nmL} / \mathrm{mL} / \mathrm{min}: \mathrm{p}- \\
\text { nitrofenol- } \beta \text {-diacetil- } \\
\text { quitobiose }\end{array}$ \\
\hline $\begin{array}{l}\text { Trichoderma harzanium } \\
\text { T198 }\end{array}$ & quitinase & $\begin{array}{l}\text { Precipitação com sulfato de } \\
\text { amônio, cromatografia de } \\
\text { afinidade com quitina } \\
\text { Filtração em gel } \\
\text { SDS-PAGE }\end{array}$ & $\begin{array}{c}28 \\
27,5\end{array}$ & $\begin{array}{l}\text { a- } 3,5 \\
\text { b- } 50{ }^{\circ} \mathrm{C} \\
\text { d- } 7,4\end{array}$ \\
\hline
\end{tabular}

Uma grande quantidade de produtos podem ser isolados e purificados da célula microbiana com auxílio da lise enzimática como, por ex. peptídeos, polissacarídeos, proteínas recombinantes, ácidos nucléicos, pigmentos, enzimas, lipídeos, entre outros. Além do potencial de aplicação na preparação de protoplastos, fusão celular e transformação de leveduras, pode-se ressaltar sua aplicação na produção de enzimas intracelulares, preparação do polissacarídeo glucana, extração alcalina de proteínas de leveduras, pré-tratamento para lise mecânica de células em Dyno-Mill, produção de extrato de levedura, extração de pigmentos de leveduras vermelhas e lise de microrganismos que provocam a cárie dentária ${ }^{8}$. A lise de célu- las de leveduras com enzimas permite seletividade na liberação de produtos, independe da escala e pode ser realizada em condições de $\mathrm{pH}$ e temperatura que não implicam na desnaturação de produtos celulares de interesse.

As enzimas líticas podem ser utilizadas para lise da parede celular de leveduras para diferentes finalidades, como preparação de extrato de levedura ${ }^{80}$; aumento da eficiência de desintegrador mecânico para extração de compostos intracelulares e ligados à célula ${ }^{46}$; aumento da digestibilidade de ração animal ${ }^{46,81}$; extração do pigmento vermelho astaxantina de Phaffia rhodozyma ${ }^{82}$; preservação de alimentos ${ }^{4,5}$; obtenção de fonte de proteína unicelular para animais e humanos ${ }^{83}$; aumento do valor alimentício de cereais quando 
Tabela 4. Clonagem e expressão de genes que codificam a produção de $\beta-1,3$ glucanases de diversos organismos

\begin{tabular}{|c|c|c|c|}
\hline Organismo & Enzima (s) & Gene (s) & Comentários \\
\hline $\begin{array}{l}\text { Bacillus circulans } \\
\text { WL- } 12^{75}\end{array}$ & $\begin{array}{l}\beta-1,3 \text { glucanases } \\
\text { B e C }\end{array}$ & GlcB & $\begin{array}{l}\text { O gene foi clonado em } E \text {. coli e a seqüência nucleotídica } \\
\text { determinada }\end{array}$ \\
\hline $\begin{array}{l}\text { Oerskovia xanthineolytica } \\
\text { LLG10974 }\end{array}$ & $\begin{array}{l}\text { Endo- } \beta-1,3 \\
\text { glucanase }\end{array}$ & Beta III & $\begin{array}{l}\text { Elucidação da seqüência primária de aminoácidos e } \\
\text { subseqüente expressão em Bacillus subtilis }\end{array}$ \\
\hline $\begin{array}{l}\text { Streptomyces matensis } \\
\text { DIC- } 108^{76}\end{array}$ & $\begin{array}{c}\beta-1,3 \text { glucanase- } \\
\text { laminarinapentaose }\end{array}$ & lph & $\begin{array}{l}\text { O gene foi clonado, a seqüência de aminoácidos da região } \\
\text { N-terminal e a seqüência total do gene foram determinadas. }\end{array}$ \\
\hline $\begin{array}{l}\text { Cellulomonas cellulans } \\
191^{69}\end{array}$ & $\beta-1,3$ glucanase & - & $\begin{array}{l}\text { A região N-terminal do gene foi seqüenciada e os resíduos } \\
\text { obtidos desta técnica foram idênticos aos obtidos da } \beta-1,3 \\
\text { glucanase da preparação comercial zymolyase }\end{array}$ \\
\hline Oerskovia xanthineolytica ${ }^{77}$ & $\beta-1,3$ glucanase & - & $\begin{array}{l}\text { Obtenção de uma E. coli recombinante para a super produção } \\
\text { da enzima }\end{array}$ \\
\hline $\begin{array}{l}\text { Lysobacter enzymogenes } \\
\text { N4-7 }\end{array}$ & $\begin{array}{l}\text { Três } \beta-1,3 \\
\text { glucanases }\end{array}$ & $\begin{array}{l}\text { GluA, gluB } \\
\text { e gluC }\end{array}$ & $\begin{array}{l}\text { Identificação e determinação da seqüência interna de } \\
\text { aminoácidos dos três genes. Atribui-se às } \beta-1,3 \text { glucanases a } \\
\text { atividade de biocontrole }\end{array}$ \\
\hline Pyricularia oryzae $e^{78}$ & $\begin{array}{l}\text { Endo- } \beta-1,3 \\
\text { glucanase }\end{array}$ & $\begin{array}{c}\text { DNAc } \\
(\text { OsGLN1) }\end{array}$ & $\begin{array}{l}\text { O DNAc foi clonado, caracterizado e expresso em E. coli. } \\
\text { A proteína recombinante obtida foi capaz de hidrolisar a } \\
\text { parede celular do fungo patógeno do arroz (Pyricularia } \\
\text { oryzae) e laminarina }\end{array}$ \\
\hline
\end{tabular}

se utilizam altas proporções de polissacarídeos sem amido ${ }^{84}$; obtenção de mananas de diferentes fontes que apresentam atividade antioxidante e antimutagênica ${ }^{85}$; melhoramento da clarificação e filtração de vinhos ${ }^{86}$; síntese de novos substratos para $\beta-1,3$ e $\beta-1,4$ glucanases por meio de reações de transglicosilação catalisadas por $\beta-1,3$ glucanases ${ }^{85}$; redução da viscosidade do produto final no processo de fabricação de cerveja ${ }^{81}$; elucidação da estrutura, composição e mecanismo da síntese da parede celular de levedu$\operatorname{ras}^{15,16,18,20,21,88-91}$.

As enzimas quitinolíticas apresentam inúmeras aplicações biotecnológicas no ramo da indústria e agricultura. As quitinases podem ser utilizadas no controle de fungos patógenos de plantas e insetos. Há também, um crescente interesse na produção de quitinooligossacarídeos biologicamente ativos através da utilização das quitinases. Essas enzimas podem ainda ser aplicadas na produção de fonte de proteína unicelular, preparação de enzimas micolíticas e na formação de protoplastos fúngicos ${ }^{92}$.

Alguns trabalhos relatam as aplicações de quitinases e $\beta-1,3$ glucanases no setor agrotecnológico. Wiwat et al..$^{93}$ produziram quitinase a partir de Bacillus circulans 41 para uso como suplemento de bioinseticida de $B$. thuringiensis para controle de larvas de lepidópteras. Zhang e Yuen ${ }^{94}$ utilizaram um sistema lítico composto por quitinase, protease, $\beta-1,3$ glucanase e lipase para controle de manchas nas folhas de centeio, causadas por Biopolaris sorokiniana.

$\beta-1,3$ glucanases e quitinases produzidas por plantas em resposta às infecções causadas por microrganismos patogênicos têm sido purificadas e utilizadas para testes de atividade antifúngica. Sela-Buurlage et al..$^{95}$ verificaram a atividade antifúngica de diferentes isoformas de quitinases e $\beta-1,3$ glucanases do tabaco contra esporos de Fusarium solani. Ji e Kùc ${ }^{96}$ observaram a atividade fungicida de $\beta-1,3$ glucanase e quitinase de pepino (Cucumis sativus L.) sobre Colleotrichum lagenarium. Beffa et al. ${ }^{97}$ verificaram que $\beta-1,3$ glucanases de plantas com atividade antifúngica apresentam função na patogênese viral, atuando sobre o vírus do tabaco de Havana 425 e sobre Nicotiniana sylvestris (vírus que causa necrose no tabaco). Kim e Hwang ${ }^{98}$ utilizaram uma $\beta-1,3$ glucanase purifi-

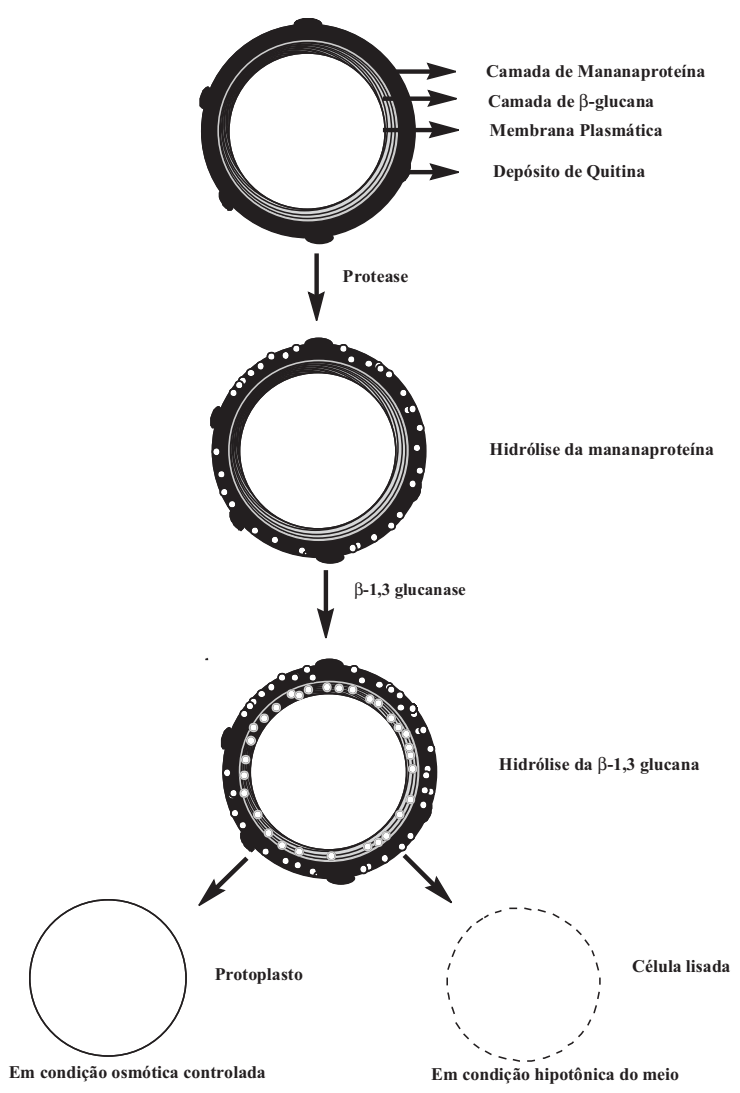

Figura 4. Lise enzimática da célula de levedura e formação de protoplasto

cada de raiz de pimenta para inibir o crescimento das hifas do fungo Phytophthora capsici. O efeito sinérgico da $\beta-1,3$ glucanase e de uma quitinase também produzida pela pimenta ocasionou inibição do crescimento das hifas de F. oxysporum var. cucumerinum e P. capsici. O mecanismo de resposta de plantas infectadas induz a produção de $\beta-1,3$ glucanases e quitinases. Essas enzimas estão rela- 
Tabela 5. Enzimas líticas envolvidas no biocontrole de fitopatógenos

\begin{tabular}{|c|c|c|}
\hline Microrganismos de controle biológico & Enzimas envolvidas & Fitopatógeno \\
\hline Pichia membranifaciens FY-101 101 & $\beta-1,3$ glucanases & Botrytis cinerea \\
\hline Thichoderma harzianum CECT $2413^{102}$ & Quitinase, $\beta$-1,3 e $\beta-1,6$ glucanase & $\begin{array}{l}\text { Rhizoctonia solani e } \\
\text { Botrytis cinerea }\end{array}$ \\
\hline Glomus mosseae e Glomus intraradices ${ }^{103}$ & $\begin{array}{l}\text { Quitinase, quitosanase, } \beta-1,3 \text { glucanase e } \\
\text { superóxido-dismutase }\end{array}$ & Phytophthora parasitica \\
\hline Rhodotorula glutinis e Cryptococcus laurentii ${ }^{104}$ & $\begin{array}{l}\beta-1,3 \text { glucanase, polifenoloxidase, fenilalanina } \\
\text { e amônia-liase }\end{array}$ & $\begin{array}{l}\text { Penicillium expansum e } \\
\text { Alternaria alternata }\end{array}$ \\
\hline Bacillus mycoides $^{105}$ e Bacillus pumilus ${ }^{106}$ & Quitinase, $\beta-1,3$ glucanase e peroxidase & Cercospora beticola \\
\hline Tilletiopsis pallescens Gokhale ${ }^{107}$ & Exo e endo $\beta-1,3$ glucanase e quitinase & Podosphaera xanthii \\
\hline
\end{tabular}

cionadas à patogênese e são indicadoras do sistema de resistência da planta. Em geral, são encontradas em compartimentos onde há lesões causadas por fungos e vírus infectantes ${ }^{99,100}$.

As enzimas líticas, principalmente $\beta-1,3$ glucanases e quitinases, também são produzidas por microrganismos que exercem função antagônica aos fitopatógenos. À essas enzimas atribuiu-se o efeito de fungitoxicidade sobre o patógeno e a eficácia do biocontrole de organismos antagonistas (Tabela 5).

\section{CONCLUSÕES}

As células microbianas podem ser rompidas por métodos mecânicos, químicos ou enzimáticos. Em condições extremas de pressão e temperatura requeridas na lise mecânica, as proteínas e outros produtos podem ser desnaturados e, desta forma, a lise enzimática da parede celular de leveduras, realizada a $35-37{ }^{\circ} \mathrm{C} \mathrm{em} \mathrm{pH} \mathrm{7,0-7,5,} \mathrm{tem-se} \mathrm{tor-}$ nado bastante atrativa. As preparações comerciais líticas apresentam custo elevado, o qual, provavelmente, está associado a procedimentos ultrapassados e onerosos. O investimento em pesquisas de produção das enzimas com indutores baratos e facilmente disponíveis e procedimentos melhorados de purificação podem ser de grande contribuição para diminuição dos custos. As enzimas líticas b-1,3 glucanases, proteases e quitinases apresentam variadas aplicações industriais e são requeridas em muitas áreas da pesquisa, o que amplia o campo de utilização dessas enzimas.

\section{AGRADECIMENTOS}

À FAPESP pelo apoio financeiro.

\section{REFERÊNCIAS}

1. Fleet, G. H.; Curr. Top. Med. Mycol. 1985, 1, 24.

2. Hartland, R. P.; Vermeulen, C. A.; Klis, F. M.; Sietsma, J. H., Wessels, J. G. H.; Yeast. 1994, 10, 1591 .

3. Klis, F. M.; Yeast. 1994, 10, 851.

4. Andrews, B. A.; Asenjo, J. A.; Biotechnol. Bioeng. 1987, 30, 628.

5. Andrews, B. A.; Asenjo, J. A.; Tibtech. 1987, 5, 273.

6. Scott, J. H.; Schekman, R.; J. Bacteriol. 1980, 142, 414.

7. Zlotnik, H.; Fernandez, M. P.; Bowers, B.; Cabib, E.; J. Bacteriol. 1984, $159,1018$.

8. Asenjo, J. A.; Andrews, B. A.; Hunter, J. B.; Lecorre, S.; Process Biochem. 1985,159

9. Hunter, J., B.; Asenjo, J. A.; Biotechnol. Bioeng. 1988, 31, 929.

10. Stratford, M.; Yeast. 1994, 10, 1741.

11. Cabib, E.; Drgon, T.; Drgonovaa, J.; Ford, R. A.; Kollar, R.; Biochem. Soc. Trans. 1997, 25, 200.

12. Bacon, J. S. D.; Farmer, V. C.; Jones, D.; Taylor, I. F.; Biochem. J. 1969, 114, 557.

13. Lampen, J. O.; A. Van. Leeuw. 1968, 34, 1.
14. Yamamoto, S.; Nagasaki, S.; Agr. Biol. Chem. 1975, 39, 1981.

15. Kapteyn, J. C.; van Egmond, P.; Sievi, E.; van Den Ende, H.; Makarow, M.; Klis, F. M.; Mol. Microbiol. 1999, 31, 1835.

16. Popolo, L.; Vai, M.; BBA-Gen. Subjects 1999, 1426, 385.

17. Kapteyn, J. C.; Mol. Microbiol. 2000, 35, 601.

18. Kapteyn, J. C.; van Den Ende, H.; Klis, F. M.; BBA-Gen. Subjects 1999, $1426,373$.

19. Lagorce, A.; Hauser, N. C.; Labourdette, D.; Rodriguez, C.; Martin-Yken, H.; Arroyo, J.; Hoheisel, J. D.; François, J.; J. Biol. Chem. 2003, 278, 20345.

20. Mrsa, V.; Ecker, M.; Cappellaro, C.; Teparic, R.; Tanner, W.; Food Technol. Biotech. 1999, 37, 21.

21. Mrsa, V.; Tanner, W.; Yeast. 1999, 15, 813.

22. Manners, D. J.; Masson, A. J.; Patterson, J. C.; Biochem. J. 1973, 135, 19.

23. Kopecká, M.; Phaff, H. J.; Fleet, G. H.; J. Cell Biol. 1974, 62, 66.

24. Kreger, D. R.; Kopecká, M.; J. Gen. Microbiol. 1976, 92, 207.

25. Hinton, D. M.; Pressey, R.; J. Am. Soc. Hort. Sci. 1980, 105, 499.

26. Majeti, N.; Kumar, R.; React. Funct. Polym. 2000, 46, 1.

27. Roberts, G. Em Physical structures; Roberts, G. A. F., ed.; Macmilian: London, 1992, p. 20.

28. Sahai, A. S.; Manocha, M. S.; Microbiol. Rev. 1993, 11, 317.

29. Bacon, J. S. D.; Gordon, A. H.; Jones, D.; Taylor, I. F.; Webley, D. M.; Biochem. J. 1970, 120, 67.

30. Doi, K.; Doi, A.; Fukui, T.; Agr. Biol. Chem. 1973, 37, 1619.

31. Obata, T.; Iwata, H.; Namba, Y.; Agr. Biol. Chem. 1977, 41, 2387.

32. Obata, T.; Fujioka, K.; Hara, S.; Namba, Y.; Agr. Biol. Chem. 1977, 41, 671.

33. Yamamoto, N.; Sato, S.; Saito, K.; Hasuo, T.; Tadenuma, M.; Suzuki, K.; Tamaoka, J.; Komagata, K.; Int. J. Syst. Bacteriol. 1988, 38, 7.

34. Yamamoto, N.; Sato, S.; Miki, H.; Park, Y.; Tadenuma, M.; J. Gen. Appl. Microbiol. 1993, 39, 261.

35. Santos, L. F.; Dissertação de Mestrado, Universidade Estadual de Campinas, Brasil, 2000.

36. Ferro, L. A.; Tese de Doutorado, Universidade Estadual de Campinas, Brasil, 2002.

37. Hasuo, T.; Yamamoto, N.; Saito, K.; Tadenuma, M.; J. Brew. Soc. Jpn. 1984, $79,510$.

38. Kitamura, K.; Yamamoto, Y.; Arch. Biochem. Biophys. 1972, 153, 403.

39. Hayashi, K.; Seino, A.; Kasumi, T.; Kubo, N.; Tsumura, N.; J. Ferment. Technol. 1981, 59, 319.

40. Hayashi, K.; Seino, A.; Kasumi, T.; Kubo, N.; Tsumura, N.; Agr. Biol. Chem. 1981, 45, 2289.

41. Pitson, S. M.; Seviour, R. J.; Macdougal, B. M.; Mycol. Res. 1997, 101, 153.

42. Pitson, S. M.; Seviour, R. J.; Macdougal, B. M.; Enzyme Microb. Technol. 1997, 21, 182.

43. Noronha, E. F.; Ulhoa, C. J.; Microbiol. Lett. 2000, 183, 119

44. Bara, M. T. F.; Lima, A. L.; Ulhoa, C. J.; FEMS Microbiol. Lett. 2003, $219,81$.

45. Khan, A.; Williams, K.; Molloy, M. P.; Nevalainen, H.; Protein Expression Purif. 2003, 32, 210.

46. Kobayashi, R.; Miwa, T.; Yamamoto, S.; Nagasaki, S.; Eur. J. Appl. Microbiol. 1982, 15, 14.

47. Yamamoto, N.; Hasuo, T.; Terauchi, T.; Saito, K.; Tadenuma, M.; J. Brew. Soc. Jpn. 1984, 79, 828.

48. Yamamoto, N.; Hasuo, T.; Saito, K.; Tadenuma, M.; Agr. Biol. Chem. 1987, 51,1541 . 
49. Vrsanská, M.; Biely, P.; Krátký, Z. Z.; Allg. Mikrobiol. 1977, 17, 465.

50. Vrsanská, M.; Krátký, Z. Z.; Biely, P.; Allg. Mikrobiol. 1977, 17, 391

51. Rowley, B. I.; Bull, A. T.; Biotechnol. Bioeng. 1977, 19, 879.

52. Bielecki, S.; Wnuk, M.; Szczesna, M.; Bobobwicz-Lassocinska, T.; Antczak, T.; Galas, E.; Biotechnol. Lett. 1989, 11, 281.

53. Gacto, M.; Vicente-Soller, J.; Villa, T. G.; J. Appl. Microbiol. 2000, 88 , 961.

54. Fleuri, L. F.; Dissertação de Mestrado, Universidade Estadual de Campinas, Brasil, 2003.

55. Nampoothiri, M. K.; Baiju, T. V.; Sandhya, C.; Sabu, A.; Szakacs, G.; Pandey, A.; Process Biochem. 2003.

56. Kenji, S.; Akira, Y.; Hajime, K.; Mamoru, W.; Mitsuaki, M.; Appl. Environ. Microbiol. 1998, 64, 3397.

57. Macwilliam, I. C.; J. Inst. Brew. 1970, 76, 525.

58. Kaneko, T.; Kitamura, K.; Yamamoto, Y.; Agr. Biol. Chem. 1973, 37, 2295.

59. Funatsu, M.; Oh, H.; Aizono, T.; Shimoda, T.; Agr. Biol. Chem. 1978, 42, 1975.

60. Prokopakis, G. J.; Liu, L. C.; Biotechnol. Bioeng. 1997, 53, 290.

61. Lechevalier, H. A.; Lechevalier, M. P. Em Bergey's Manual of Sistematic Bacteriology; Lechevalier, P.; Lechevalier, eds.; Willians e Willians, 1986, p. 1489.

62. Kitamura, K.; Agr. Biol. Chem. 1982, 46, 2093.

63. Usui, T.; Oguchi, M.; Agr. Biol. Chem. 1986, 50, 535.

64. Ryan, E.; Ward, O.; Process Biochem. 1988. 12

65. Parrado J.; Escudero, P. R.; Conejero-Lara, F.; Kotik, N.; Ponting, C. P.; Asenjo, J. A.; Dobson, C. M.; Biochim. Biophys. Acta 1996, 1296, 145.

66. Saeki, K.; Iwata, J.; Yamazaki, S.; Watanabe, Y.; Tamai, Y.; J. Ferment. Bioeng. 1994, 78, 407.

67. Thrane, C.; Tronsmo, A; Jensen, D. F.; Eur. Plant Pathol. 1997, 103, 331.

68. Noronha, E. F.; Ulhoa, C. J.; Microbiol. Lett. 2000, 183, 119.

69. Soares, G. A. M.; Tese de Doutorado, Universidade Estadual de Campinas, Brasil, 2002.

70. Miyanishi, N.; Hamada, N.; Kobayashi, T.; Imada, C.; Watanabe, E.; J. Biosci. Bioeng. 2003, 95, 45.

71. Chen, C.; Hsu, M.; Jiang, S.; Enzyme Microb. Technol. 1997, 20, 191.

72. De Siqueira Pinto, A.; Barreto, C. C.; Schrank, A.; Ulhoa, C. J.; Henning Vainstein, M.; Can. J. Microbiol. 1997, 43, 322

73. Deane, E. E.; Whipps, J. M.; Lynch, J .M.; Peberdy, J. F.; Biochim. Biophys. Acta 1998, 1383, 101.

74. Ferrer, P.; Hedegaard, L.; Halkier, T.; Diers, I.; Savva, D.; Asenjo, J. A.; Ann. N. Y. Acad. Sci. 1996, 782, 555.

75. Okada, T.; Aisaka, M.; Ainda, K.; Nikaidou, N.; Tanaka, H.; Watanabe, T.; J. Ferment. Bioeng. 1995, 80, 229.

76. Nakabayashi, M.; Nishijima, T.; Ehara, G.; Nikaidou, N.; Nishihashi, H., Watanabe, T.; J. Ferment. Bioeng. 1998, 85, 459.

77. Salazar, O.; Molitor, J.; Lienqueo, M. E.; Asenjo, J. A.; Protein Expression
Purif. 2001, 23, 219

78. Palumbo, J. D.; Sullivan, R. F.; Kobayashi, D. Y.; J. Bacterial. 2003, 185, 4362 .

79. Akiyama, T.; Pillai, M. A.; Plant Sci. 2001, 161, 1089.

80. Yamamoto, Y.; Fujino, S.; Kitamura, K.; Kaneko, T.; J. Ferment. Technol. 1974, 52, 828

81. Planas, A.; Biochim. Biophys. Acta 2000, 1543, 361.

82. Okagbue, R. N.; Lewis, M. J.; Biotechnol. Lett. 1983, 5, 731.

83. Nakajima, T.; Konno, R.; Nishihara, H.; Matsuda, K.; J. Ferment. Technol. 1988, 66, 245.

84. Richter, G.; Stolken, B.; Hafner, B.; Okologische Aspekte Extensiver Landbewirtsshatung 1992, 419.

85. Krizková, L.; Duracková, Z.; Sandula, J.; Sasinková, V.; Krajcovic, J.; Mutat. Res. 2001, 497, 213.

86. Elvig, S. G.; Pedersen, P. B.; Regul. Toxicol. Pharm. 2003, 37, 11.

87. Borris, R.; Krah, M.; Brumer, H.; Kerzhner, M. A.; Ivanen, D. I.; Eneyskaya, E. V.; Elyakova, L. A.; Shishlyannikov, S. M.; Shabalin, K. A.; Neustroev, K. N.; Carbohydr. Res. 2003, 338, 1455.

88. Kollar, R.; Petrakova, E.; Ashwell, G.; Robbins, P.W.; Cabib, E.; J. Biol. Chem. 1995, 270, 1170.

89. Kollar, R.; Reinhold, B. B.; Petrakova, E.; Yeh, H. J. C.; Aswell, G.; Drgonova, J.; Kapteyn, J. C.; Klis, F. M.; Cabib, E.; J. Biol. Chem. 1997, 272, 17762 .

90. Southard, S. B.; Specht, C.A.; Mishra, C.; Chen-Weiner, J.; Robbins, P. W.; J. Bacteriol. 1999, 181, 7439.

91. Santos, B.; Snyder, M.; Mol. Biol. Cell. 2000, 11, 435.

92. Patil, R. S.; Ghormade, V.; Deshpande, M. V.; Enzyme Microb. Technol. 2000, 26, 473 .

93. Wiwat, C.; Siwayaprahm, P.; Bhumiratana, A.; Curr. Microbiol. 1999, 39, 134.

94. Zhang, Z.; Yuen, G. Y.; Phytopathol. 1999, 89, 817.

95. Sela-Buurlage, M. B.; Ponstein, A. S.; Bres-Vloemans, S. A.; Melchers, L. S.; van Den Elzen, P.; Cornelissen, B.; Plant Physiol. 1993, 101, 857.

96. Ji, C.; Kùc, J.; Physiol. Mol. Plant P. 1996, 49, 257.

97. Beffa, R. S.; Hofer, R. M.; Thomas, M.; Meins Jr., F.; The Plant Cell. 1996, $8,1001$.

98. Kim, Y. J.; Hwang, B. K.; Physiol. Mol. Plant P. 1997, 50, 103.

99. Kang, Z.; Buchenauer, H.; Physiol. Mol. Plant P. 2002, 60, 141.

100. Burketová, L.; Stillerová, K.; Feltlová, M.; Physiol. Mol. Plant P. 2003, $63,47$.

101. Masih, E. I.; Paul, B.; Curr. Microbiol. 2002, 44, 391.

102. Rey, M.; Delgado-Jarana, J.; Benítez, T.; Appl. Microbiol. Biot. 2001, 55, 604.

103. Pozo, M. J.; Cordier, C.; Dumas-Gaudot, E.; Gianinazzi, S.; Barea, J. M.; Azcón-Aguilar, C.; J. Exp. Bot. 2002, 53, 525.

104. Qin, G. Z.; Tian, S. P.; Xu, Y.; Wan, Y. K.; Physiol. Mol. Plant P. 2003, $62,147$.

105. Bargabus, R. L.; Zidack, N. K.; Sherwood, J. E.; Jacobsen, B. J.; Physiol. Mol. Plant P. 2002, 61, 289.

106. Bargabus, R. L.; Zidack, N. K.;Sherwood, J. E.; Jacobsen, B. J.; Biol. Control. 2003.

107. Urquhart, E. J.; Punja, Z. K.; Can. J. Microbiol. 2002, 48, 219. 